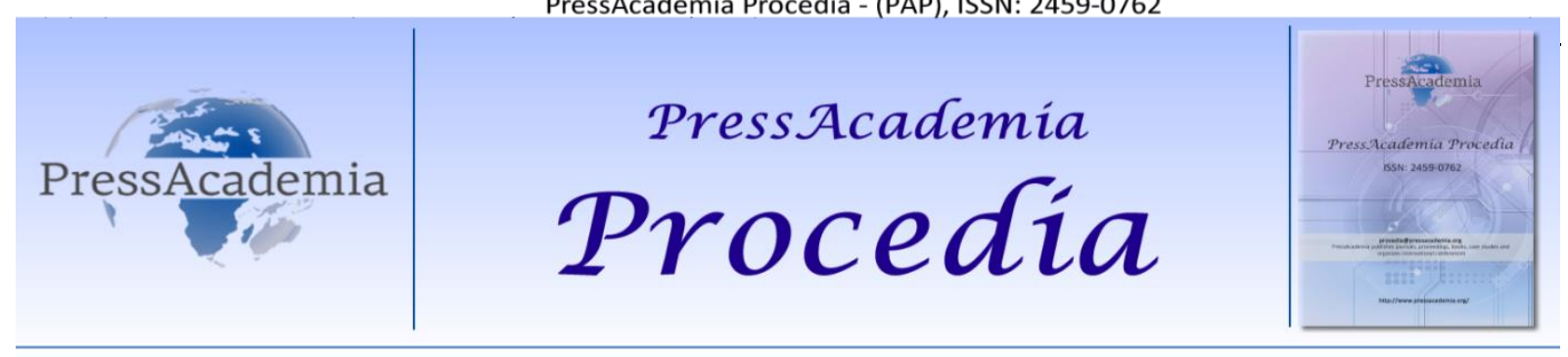

Global Business Research Congress (GBRC), May 24-25, 2017, Istanbul, Turkey.

\title{
AIRLINES AND RISK MANAGEMENT WITH FINANCIAL RATIOS: TURKISH AIRLINES CASE STUDY
}

\author{
DOI: 10.17261/Pressacademia.2017.396 \\ PAP-GBRC-V.3-2017(11)-p.96-103
}

\section{Burcu Sakiz}

İstanbul Aydın Üniversitesi, Sosyal Bilimler Enstitüsü İşletme Ana Bilim Dalı, Florya, İstanbul, Türkiye. Burcubaydar78@gmail.com

To cite this document

Sakız, B. (2017). Airlines and risk management with financial ratios: Turkish airlines case study. PressAcademia Procedia (PAP), V.3, p.96103

Permemant link to this document: http://doi.org/10.17261/Pressacademia.2017.396

Copyright: Published by PressAcademia and limited licenced re-use rights only.

\begin{abstract}
Air transport which is the fastest mode of transport can be accepted as the gift of the 20th century to the world. As our global economy grows ever more linked, air transportation is the factor that brings people together. The growing air transportation in all over the world and espacially in Turkey has increased the importance of airline passenger and cargo operations and has brought intense competition in recent years. Under heavy competition, it is of utmost importance to have sustainable success of an ever-evolving and growing market by accurately assessing the financial performance and risks of businesses. Even though there are financial ratios which are generally used for services, manufacturing and raw materials sectors widely, there are a lot of metrics and indicators specific to the airline industry used to assess the financial status of airlines. Traditional ratio analysis is a frequently used for financial analysis and difeerent ratios are used to match the type of analysis that needs to be done. However, it can be benefical to group several indicators together into a statistical model. In this paper, after literature review, one of the most important financial risk evaluation models developed for airlines called Airscore model and also one of the most popular and practical model that is Altman's bankruptcy prediction model ( $Z^{\prime \prime}$-score) are examined and its application with Turkish Airlines' financial data is evaluated.
\end{abstract}

Keywords: Financial ratios, financial analysis, airline sector, bankruptcy prediction models, Z" score.

JEL Codes: G30, G32, G33

\section{HAVAYOLLARI VE FINANSAL ORANLAR KULLANILARAK RISK YÖNETIMI: TÜRK HAVA YOLLARI VAKA ÇALIŞMASI}

\section{ÖZET}

En hızlı ulaşım yolu olan hava taşımacılı̆ı, 20. yüzyılın dünyaya armağanı olarak kabul edilebilir. Küresel ekonomimiz giderek daha fazla bağlantı kurduğundan, hava taşımacılığı insanları bir araya getiren faktördür. Dünyanın her yerinde ve özellikle Türkiye'de havayolu taşımacılığının artması, havayolu yolcu ve yük operasyonlarının önemini arttırmış ve son yıllarda yoğun rekabete neden olmuştur. Yoğun rekabet ortamında, işletmelerin mali performansını ve risklerini doğru bir şekilde değerlendirmek, sürekli gelişen ve büyüyen bir pazarda sürdürülebilir başarı elde etmek için çok önemlidir. Hizmet, imalat ve ham madde sektörleri için genel olarak kullanılan mali oranlar olmasına rağmen, havayollarının mali durumunu değerlendirmek için havayolu endüstrisine özgü çok sayıda metrik ve gösterge bulunmaktadır. Geleneksel oran analizi, finansal analiz yapmak için sıklıkla uygulanmaktadır ve yapılan analiz türüne göre farklı oranlar kullanılmaktadır. Bununla birlikte, birkaç göstergeyi birlikte gruplamak ve istatistiksel bir modele koymak faydalı olabilir. Bu çalışmada, literatür taraması yapıldıktan sonra havayolları için geliştirilen en önemli değerlendirme modellerinden biri olan Airscore modeli ve bununla birlikte en popüler ve pratik modelden biri olan Altman'ın iflas öngörme modeli (Z' score) incelenmiş, Türk Hava Yolları A.O'nun mali verileri ile uygulama yapılarak ele alınmıştır.

Anahtar Kelimeler: Finansal oranlar, finansal analiz, havayolu sektörü, iflas tahmin modelleri, Z" skor. JEL Kodları: G30, G32, G33 


\section{GiRiş}

Yaklaşık olarak 2,5 milyon yıla dayandığı tahmin edilen tarihinde insanoğlu kanat, paraşüt, uçurtma ve planörler ile dünyanın çeşitli yerlerinde çeşitli uçuş denemeleri yapmış, tarım toplumundan sanayi toplumuna geçilmesi ile birlikte zaman içinde balonlar ve zeplinlerin icadından sonra ilk motorlu uçuşlar sanayi devriminin ardından 20. yüzyılda gerçekleştirmiştir. 1903 yılının sonlarında Wright Kardeşlerin gerçekleştirdiği havadan ağır motorlu uçuş, mihenk taşlarından olmuştur(McCollough,2016). Zaman içinde çoğalan şehirleşme, nüfus artışı ve sanayileşmenin yaygınlaşmasına paralel olarak taşıma ve ulaştırma sistemleri de hız, düşük maliyet, emniyet, gerekli yasal çerçeve ve konfor açısından hızlı bir gelişim göstermiştir. Teknolojideki ilerleme ve sürekli geliştirilme yapıması ile motorlu uçaklar ikinci dünya savaşından sonra askeri olarak değil daha çok ticari olarak sivil havacılıkta kargo ve yük taşımacılı̆̆ında kullanılmaya başlamışlardır.

Dünyada ve ülkemizde son yıllarda giderek artan havayolu taşımacılığı, havayolu yolcu ve kargo taşıma işletmelerinin önemini giderek arttırmakta, ulusal ve uluslararası havayolları pazarında oldukça yoğun bir rekabeti beraberinde getirmektedir. Yoğun rekabet altında işletmelerin finansal performanslarının ve risklerinin doğru yöntemler ile analiz edilerek değerlendirilmesi, sürdürülebilir başarıyı yakalamak için büyük bir önem taşımaktadır. Taşımacılık sektörünün önemli bir bölümünü oluşturan hava taşımacılığı; insan, yük ya da postanın bir hava aracı vasıtası ile yer değiştirmesini sağlayan hizmet olarak tanımlanabilir (Gerede, 2002). Havayolu sektöründe faaliyet gösteren işletmelerin finansal durumlarını değerlendirebilmek için tüm sektörlerde değerlendirme yaparken kullanılan finansal oranların yanında, sektöre özel bir takım oran ve göstergeler de kullanılmaktadır. Bu oranların ve göstergelerin hesaplanarak geçmiş dönemler ve yıllar için karşılaştırılması, ileriye yönelik olarak risklerin değerlendirilmesi, tahminlerin yapılması, raporlanması, gereken durumlarda istenen senaryoların işletilip geleceğe yönelik simülasyonlar yapılması; havayolu finans yöneticilerine, analistlere ve ilgililere işletmenin finansal durumunu daha iyi değerlendirme, görebilme ve daha sağıklı olarak planlama yapabilme, doğru kararlar alma olanağı verecektir.

Havacılıkta büyümeyi sürdürürken finans fonksiyonu açısından yapılan çalışmalar; gelir yönetimi yaklaşımı, birim koltuk kilometre üzerinden satış ve maliyet analizleri, maliyetlerdeki çeşitlilik ve artışlar, makro ekonomik düzeydeki parametrelerin faaliyetlere ve finansal yapıya yansıması vb. şeklindedir. Dünyadaki çeşitli gelişmeler başta yakıt maliyetleri olmak üzere, kur, faiz, likidite vb. riskler üzerinde etkili olmaya başlamıştır. Karlıık ve mali yapıdaki bozulmalar, birçok havayolu işletmesinde risk yönetiminin önemini ortaya çıkartmıştır(Karaer,2015). Havacılık sektörüne özel yapılan çeşitli çalışmalarda analistler, işletmeler için ana olarak kaynaklar (işgücü, sermaye, yakıt), üretilen çıktı (araç/saat, araç/km veya mil) ve hizmetin tüketimidir (yolcu sayısı, yolcu/km veya mil, faaliyet gelirleri v.b). şeklinde sınıflandırıan üç temel faktör üzerinde yoğunlaşmıştır. Doğrudan havayolu endüstrisine ilişkin özel gösterge ve oranların eksikliği bu endüstride faaliyet gösteren işletmelerin doğru bir biçimde değerlendirilmesi imkanını sınırlandırmaktadır (Akkaya,2004).

Çalışmada, Altman Z" skor ve Airscore modelleri incelenmiş, Türk Hava Yolları A.O mali verileri ile uygulama yapılarak değerlendirilmiştir.

\section{LITERATÜR INCELEMESI}

İşletmelerin finansal performanslarının değerlendirilmesinde yaygın olarak yüzde yöntemi ile analiz, finansal tabloların karşılaştırmalı analiz, trend ve rasyo analizi gibi yöntemlerin kulanıldığı görülmektedir. Finansal risk yönetimi, finansal göstergelerin işletmelerin özel durumlarıyla ilişkilendirilmesi ile alınan kararların devamlı gözden geçirilmesi, gereken hallerde yeniden değerlendirerek yeni önlemlerin alınması şeklinde dinamik bir süreci içerir(Sayılgan, 1995). İ̧letmelerin finansal olarak başarısız olduğuna hükmetmek için aşağıda verilen dört durumdan birinin var olması yeterli görülmektedir (Altman,Hotchkiss, 2006):

- Devam eden faaliyetlerin durdurulması veya iflası,

- Haciz,icra veya mülkiyete rehin gibi olaylara maruz kalınması,

- Tasfiye ve henüz yerine getirilmemiş yükümlülüklerini yerine getirmekten kaçınmak, kayyum atanması veya yeniden yapılandırma gibi mahkeme süreçleri yaşıyor olmak,

- Borç verenler ile yükümlülüklerin vadesi ve ödenmesi konusunda gönüllü olarak uzlaşmaya gitmek.

Analistler temel olarak finansal sağlık göstergeleri için çeşitli finansal oranlar hesaplamışlardır. Bunlar Altman’a göre şu şekilde sınıflandırılabilir:

- Likidite oranları

- $\quad$ Aktivite(faaliyet) oranları

- Karlılık oranları

- Finansal yapı oranları(mali oranlar)

- Piyasa oranları

Yakın zamanda analistler bu oranları kurdukları modellerle birleştirerek finansal riski, finansal zorlukları göstermek ve iflas durumunu tahmin etmek için kullanmaya başlamışlardır. İşletmelerin finansal zorluklara karşı olan gücünü belirlemek için 
birçok farklı sayısal yöntem kullanıldığı görülmektedir. Bu yöntemlerden bazıları yöntemleri ayrı ayrı kullanırken, bazı çalışmalar ise yöntemlerin tahmin performanslarının karşılaştırmasını yapmışlardır (Yıldız,2014). Yöntemler şöyle sınıflandırılabilir:

- Tek değişkenli istatistiksel yöntemler,

- Çok değişkenli istatistiksel yöntemler (ayırma yöntemi, lojistik regresyon yöntemi),

- Yapay sinir ağları,

- Optimizasyon modelleri.

Literatürde finansal risk değerlendirme ve iflas durumunu tahmin etme modelleri olarak havayollarının kullanabileceği 6 tane ana modelden bahsedilmektedir (Gritta v.d 2008):

- Altman Model

- $\quad$ Altman Zeta Model

- $\quad$ Airscore Model

- $\quad$ Pilarski Model

- Gudmunsson Model

- Yapay Zeka Modelleri

Bu modellerden Altman tarafından geliştirilen ilk iki model her sektöre uygulanabilen modeller olurken, diğerleri havayolu endüstri için geliştirilmiş havayolu verileri ile kullanılan modellerdir. (Gritta vd., 2008:194). Referans değerler olarak çoğunlukla mutlak finansal göstergelerden ziyade rasyolar kullanılmaktadır. Göstergeler ve referans değerler bulunduktan sonra yapılması gereken iş, ilgililerin kendi işletmelerine ait değerleri referans değerlerle karşılaştırması ve aradaki benzerlik ve farklııkların nedenlerini yorumlayabilmesidir. Bu göstergeler ve referans değerleri, esas itibariyle "Faaliyet alanımızda rekabet gücü olan bir işletme olabilmemiz için nasıl bir performans göstermemiz gerekir?" sorusunu cevaplandırabilmeyi sağlarlar (Dobbins vd., 2000:14). Akkaya (2004) Fend ve Wang'ın 2000 yılında yaptığı çalışmayı baz alarak uyarladığı çalışmasında havacılık işletmelerine özel olarak uçuş teçhizatı ve faiz giderleri, performansın değerlendirilebilmesi için finansal faktörler içerisine almıştır. Bununla birlikte stoklar ürünün somut olmaması ve hizmetin depolanamaması nedeniyle finansal faktörler içerisinde değerlendirilmemektedir. Havayolu işletmeleri için performans değerlendirmede kullanılabilecek veriler aşağıdaki tabloda verilmiştir.

Tablo 1 : Havayolu İşletmeleri için Performans Değerlendirmede Kullanılabilecek ????

\begin{tabular}{|l|l|l|}
\hline Sınıflandırma & Değerlendirme Kategorisi & Değerlendirme Kalemi \\
\hline Girdi & İşücü & İ̧̧ücü Sayısı \\
\hline & Uçak (Filo) & Uçak Sayısı (Filo Sayısı) \\
\hline \multirow{2}{*}{ Çıktı } & Varlıklar & $\begin{array}{l}\text { Dönen Varlıklar } \\
\text { Uçuş Techizatı } \\
\text { Duran Varlıklar } \\
\text { Toplam Varlıklar }\end{array}$ \\
\hline & Sermaye & $\begin{array}{l}\text { Toplam Sermaye } \\
\text { Özsermaye }\end{array}$ \\
\hline & Ulaştırma (Taşıma) Çıktıları & $\begin{array}{l}\text { Uçuşlar } \\
\text { Kilometre Sayısı } \\
\text { Kilometre Başına Koltuk Sayısı } \\
\text { Satılabilecek Koltuk Sayısı }\end{array}$ \\
\hline & & $\begin{array}{l}\text { Kısa Vadeli Borçlar } \\
\text { Uzun Vadeli Borçlar } \\
\text { Toplam Borçlar }\end{array}$ \\
\hline \multirow{2}{*}{ Tüketim } & Borçlar & $\begin{array}{l}\text { Faaliyet Giderleri } \\
\text { Faiz Giderleri }\end{array}$ \\
\hline & Giderler & $\begin{array}{l}\text { Yolcu Sayısı } \\
\text { Kilometre Başına Yolcu Sayısı }\end{array}$ \\
\hline & Yolcu & $\begin{array}{l}\text { Faaliyet Karı (Zararı) } \\
\text { Faiz ve Vergi Öncesi Kar } \\
\text { Vergi Öncesi Kar } \\
\text { Net Kar (Zarar) }\end{array}$ \\
\hline & Kar / Zarar & \\
\hline
\end{tabular}

Kaynak: Akkaya (2004) 
Havayollarının karşı karşıya bulunduğu riskler açısından bakıldığında ise Topçu, yaptığı araştırma sonuçlarına göre havayolu risk tablosunu aşă̆ıdaki şekilde özetlemiştir (Top̧̧u, 2010).

Tablo 2: Havayolu Risk Gruplandırması

\begin{tabular}{|l|l|l|l|}
\hline FiNANSAL RISKLER & STRATEJiK RiSKLER & OPERASYONEL RISKLER & DIŞSAL RISKLER \\
\hline Faiz Oranı & Yönetim Yapısı & Satış Pazarlama & Iş İdaresi Standartları \\
\hline Döviz Kuru & Uyum ve Performans & E-Ticaret & Ahlak \\
\hline Emtia (Akaryakıt) Fiyatı & Kurumsal Kültür & Gelir Ücret Yönetimi & Hile \\
\hline Kredi (Likidite) & Stratejik Planlama & Sık Uçuş Programları & Hukuki \\
\hline Muhasebe-Raporlama & Arge & Müşteri ilişkileri & Sözleşmeler \\
\hline Vergi & Teknoloji İmkanları & Satınalma Tedarik & Havacılık Kuralları \\
\hline Sermaye Yapısı & Anahtar İlişki Yönetimi & Insan Kaynakları & IATA \\
\hline Kredi Derecelendirme & Ittifaklar & Bilgi işlem Teknoloji & Yerel Otoriteler \\
\hline Hisse Değeri & Anlaşmalar & Uçak Bakımları & Sendikal Haklar \\
\hline Genel Maliyet Artışları & Uçak Üreticileri & İş Sürekliliği Planlama & Sağlık ve Emniyet \\
\hline Bütçe Aşımı & Acentalarla Ilişkiler & Uçuş Planlama & Katastrofik \\
\hline Mevsimsel Dalgalanma & Temel İnsiyatifler & Yer Hizmetleri & Terör-Sabotaj \\
\hline Aktif Pasif Yönetimi & Vizyon ve Yönetim & Uçuş Ekibi Planlama & Çevresel \\
\hline Finansal Ürünler & Teknoloji Uyum & Rekabet & Karbon Ticareti \\
\hline Finansal Kiralama & Birleşme Devralma & Kargo Operasyonları & Üçüncü Taraf yük. \\
\hline Operasyonel Kiralama & Marka ve İletişim & Uçuş Güvenliği & Politik Ortam \\
\hline Kaynak: Topçu (2010) & & & \\
\hline
\end{tabular}

Havayollarını değerlendirirken veya birbirleri ile kıyaslama yaparken kullanılan çeşitli göstergeler bulunmaktadır. Bu göstergeler Finansal ve Finansal Olmayan göstergeler olarak ikiye ayrılır. THY A.O Faaliyet Raporlarınan derlenen göstergelerden önemlileri şu şekilde sınıflandırılabilir (Url, 2017).

Tablo 3: Operasyonel Veriler ve Temel Oran ve Göstergeler Tablosu

\begin{tabular}{|l|l|}
\hline Temel Oran ve Göstergeler & Operasyonel Veriler \\
\hline Likidite Oranları & Yolcu Sayıları \\
\hline -Cari Oran & Kilometre başına gelir \\
\hline -Asit Test Oranı & Arz edilen koltuk kilometer \\
\hline -Nakit Oranı & Arz edilen ton kilometer \\
\hline Borçluluk Oranları & Ücretli Yolcu-Kilometre \\
\hline - Borç/Özkaynaklar & Ücretli Ton-Kilometre \\
\hline - Net Borç/Özkaynaklar & Doluluk Oranı \\
\hline - Net Borç/FAVÖK & Çalışan Sayısı \\
\hline -Toplam Borç/Varlıklar & Filo Tipi ve Büyüklüğü \\
\hline -Toplam Borç/Ciro & Filo yaşı \\
\hline Şirket Değeri Göstergeleri & \\
\hline -Şirket Değeri/FAVÖK & Arzedilen Koltuk Kilometre başına elde edilen birim gelir \\
\hline & Arzedilen Koltuk Kilometre başına birim gider \\
\hline -Piyasa Değeri/Defter Değeri & \\
\hline
\end{tabular}




\begin{tabular}{|l|l|}
\hline -Fiyat/Kazanç & Ortalama Bacak Uzunluğu (ASL- Average Stage length) \\
\hline Karlıık Oranları & \\
\hline -Net Kar Marjı & \\
\hline -FVÖK Marıı & \\
\hline -FAVKÖK Marjı & \\
\hline -Özkaynak Karıı̆ı̆̆(ROE) & \\
\hline -Aktif Karılıı̆ı(ROA) & \\
\hline
\end{tabular}

Kaynak: THY A.O Faaliyet Raporları (Url, 2017)

Literatür araştırmasından görüleceği gibi, finansal performans ve risk belirlemede parametre ve anahtar başarı göstergelerini belirlemede varılmış bir görüş birliği henüz bulunmamaktadır. Bazı araştırmacılar yalnızca finansal veriler ile değerlendirme yaparken bazıları performans değerlendirme ve geleceğe yönelik tahmin yapabilmek için finansal olmayan verilerden yararlanmaktadır. Bazılarına göre ise bu veriler hep birlikte kullanıldıklarında daha sağlıklı sonuçlar alınmaktadır. Airscore ve Altman modelleri, finansal başarısızlık tahmini konusunda yapılan ilk ve en önemli çalışmalardan biri olarak kabul edildiğinden bu çalışma kapsamında ayrıntı ile ele alınmıştır.

\section{VERI VE YÖNTEM}

Araştırmada kullanılan veriler, Türk Hava Yolları A.O bilanço, gelir tablosu ve trafik verilerinden elde edilmiştir. Altman Z" skor ve Airscore modellerine göre hesaplamalar yapılmıştır.

\subsection{Altman Modeli}

1968 yılında akademisyen Edward Altman tarafından geliştirilen model, işletmelerin içerisinde bulunduğu mali sıkıntıyı ölçümleyip iflasa yakınlığını ortaya koymaktadır. Altman 22 ayrı finansal oranı likidite, karlılık, kaldıraç, ödeyememe ve faaliyet oranları olmak üzere toplam beş kısma ayırmıştır ve bundan bir model oluşturmuştur (Altman,1968) . Çalışmasında çok değişkenli diskriminant analizini kullanmıştır. 33 iflas etmiş, 33 iflas etmemiş imalat sektöründe faaliyet gösteren toplam 66 işletmeyi baz alınmıştır. 5 tane oranı içeren tahmin modeli ile başarısızlığı ölçmüştür. Formül ve değişken açıklamaları şu şekildedir:

$$
Z=1.2 \mathrm{~T}_{1}+1.4 \mathrm{~T}_{2}+3.3 \mathrm{~T}_{3}+0.6 \mathrm{~T}_{4}+0.999 \mathrm{~T}_{5}
$$

- $\quad \mathrm{T}_{1}=$ Çalışma sermayesi / Toplam Varlıklar: İşletmenin büyüklüğü ile likit varlıkları arasındaki ilişkiyi gösterir, yani toplam varlıklara göre dönen varlıklardaki azalmayı yansıtır. Likiditeyi ve büyüklük özelliğini dikkate alır. Dönen varlıklardan kısa vadeli borçlar çıkarıldıktan sonra elde edilen sayının toplam varlıklara bölünmesi ile bulunur.

- $\mathrm{T}_{2}=$ Alıkonmuş karlar / Toplam Varlıklar: İşletmenin köklülüğü ve gelir yaratma becerisini gösterir. Firmanın faaliyette bulunduğu süre içindeki kazanma gücünü yansıtan karlılığı ölçmektedir. Bu nedenle faaliyette bulunan döneme karşı duyarlıdır.

- $\quad \mathrm{T}_{3}=$ Faiz ve vergi öncesi kar / Toplam Varlıklar : İşletmenin operasyonel karlııı̆ını gösterir. Vergi ve kaldıraç etkisi olmadan faaliyet etkinliğini ölçmektedir. Uzun dönemli ayakta olma durumunun göstergesi olan faaliyet kazançlarını gösterdiğinden özellikle finansal başarısızlıkla karşılaşan işletmeler için önemlidir.

- $\quad \mathrm{T}_{4}=$ Toplam Piyasa Değeri / Toplam Yükümlülükler: Piyasanın bakış açısını da dikkate alarak işletmenin değerine olan algıyı ölçer. Bu firma varlıklarının ne kadar düşebileceğinin ölçüsüdür ve tehlike sinyali olduğunda güvenli fiyat dalgalarını yansıtan piyasa boyutunu göstermektedir.

- $\quad \mathrm{T}_{5}=$ Toplam Satışlar / Toplam Varlıklar: Varlık devir hızını ortaya koymaktadır. Firma varlıklarının satışlara dönüştürme gücünü ölçen standart toplam varlık devir hızıdır. Endüstriden endüstriye büyük farklılıklar göstermekle birlikte rekabetçi şartlarla mücadelede yönetimin kabiliyetini göstermektedir.

Eğer Z-score değeri,

- $\quad$ >2.99 ise işletme güvenli alanda,

- $1.81<Z<2.99$ ise işletme gri alanda,

- <1.81 ise işletme sıkıntı alanındadır(iflas olasılıklı) sonucuna varılmaktadır.

Altman işletmelerin iflasından bir yıl öncesi için \%95, ikinci yıl için ise \% 83 oranında doğru sınıflama yapmıştır. Burada dikkat edilmesi gereken nokta, çalışmasında kullanılan oranlar imalat sektöründe faaliyet gösteren şirketler için hazırlandığından 
ulaştırma gibi bir sektörde uygulanabilirliğe sahip olmamasıdır. Altman çalışmasında modelini tüm işletmelere uygulanamama gibi aldığı eleştirilerden sonra modelini geliştirmiştir. $Z^{\prime}$ modelini özel endüstri firmaları için, $Z^{\prime \prime}$ modelini de imalatçı olmayan ve hizmet işletmeleri için geliştirmiştir (Altman, 2000:14).

$Z^{\prime \prime}$ Skor $=6.56 \mathrm{~T}_{1}+3.26 \mathrm{~T}_{2}+6.72 \mathrm{~T}_{3}+1.05 \mathrm{~T}_{4}$ (özel imalat işletmesi olmayan işletmeler)

Altman Z skor modeli işletmelerin olası iflas durumlarını tahmin etmeye, öngörmeye yönelik geliştirilmiş bir model olması ile birlikte, şirketlerin finansal güçlerini değerlendirmede ve kredi sağlayıcılar ile borç verenlerin yatırım kararlarını vermelerine yardımcı olabilecek bir yaklaşım olarak da kabul edilmektedir (Hauschild, 2013).

Eğer Z" score değeri,

- $\quad$ 2.6 ise işletme güvenli alanda,

- $1.1<Z<2.6$ ise işletme gri alanda,

- $<1.1$ ise işletme sıkıntı alanındadır sonucuna varılmaktadır.

\subsection{Airscore Modeli}

Havacılık sektörüne özel yapılan çeşitli çalışmalarda ortaya konan ilk modellerden biri Airscore modelidir. Modelin \%76 ile \% 83 arasında doğruluk payı vardır. Birden fazla "gri alan" tanımlıdır. Her ne kadar küçük ve büyük havayolu taşıyıcıları için geliştirilmiş olsa da, model büyük havayolu taşıyıcı işletmeleri için yanlı sonuçlar vermekle eleştirilmektedir. Formülü aşağıda verilmiştir (Gritta vd.,2008).

AIRSCORE $=-.34140 \mathrm{~T} 1+.00003 \mathrm{~T} 2+.36134 \mathrm{~T} 3$

- $\quad$ T1= Faiz / Toplam yükümlülükler: toplam yükümlülükler için ödenecek olan faiz yükünü yansıtır.

- $\quad \mathrm{T} 2=$ Mil başına faaliyet geliri: hava mili başına gelir durumu hakkında bilgi verir

- T3= Özkaynaklar / Toplam yükümlülükler : firma değeri ve borçlar konusunda ilişkiyi gösterir.

Hesaplanan değerin 0.03 den büyük olması sağlık, -0,095 ten küçük olması sıkıntı işaretidir(Clarke v.d, 2004).

\section{BULGULAR VE TARTIŞMA}

Bu çalışmanın uygulama kısmında, Türkiye'nin ilk ve tek full servis sağlayıcısı havayolu olan Türk Hava Yolları Anonim Ortaklığı'na ait ait son 3 seneyi içeren Airscore ve Altman Z"' score değerleri hesaplanmıştır. Rriskleri göstermek için ele alınan Altman Z" ve Airscore modellerine ait hesaplamalarda aşağıdaki veriler ve rasyolar kullanılmıştır.

Tablo 4: Uygulamada Kullanılan Altman Z" ve Airscore için Rasyo ve Göstergeler

\begin{tabular}{|l|l|}
\hline Risk Modeli & Parametreler \\
\hline ALTMAN Z" & Çalışma sermayesi / Toplam Varlıklar \\
\hline ALTMAN Z" & Alıkonmuş karlar / Toplam Varlıklar \\
\hline ALTMAN Z" & Faiz ve vergi öncesi kar / Toplam Varlıklar \\
\hline ALTMAN Z" & Toplam Piyasa Değeri / Toplam Yükümlülükler \\
\hline AIRSCORE & Faiz / Toplam yükümlülükler \\
\hline AIRSCORE & Mil başına faaliyet geliri \\
\hline AIRSCORE & Özkaynaklar / Toplam yükümlülükler \\
\hline
\end{tabular}

Türk Hava Yolları A.O finansal verileri kullanılarak hesaplanan Z" score modeline ait çeyrek dönemlik sonuçlar aşağıdaki gibi hesalanarak tablo ve grafik olarak verilmiştir.

Tablo 5: Altman Z' Modeli- Türk Hava Yolları (THY) Anonim Ortaklığı 2014-2016 Çeyrek Dönem Hesaplamaları

\begin{tabular}{|c|c|c|c|c|c|c|c|c|c|c|c|}
\hline & $\begin{array}{r}\text { Ç3 } \\
2016\end{array}$ & $\begin{array}{r}\text { Ç2 } \\
2016\end{array}$ & $\begin{array}{r}\text { Ç1 } \\
2016\end{array}$ & $\begin{array}{r}\text { Ç4 } \\
2015\end{array}$ & $\begin{array}{r}\text { Ç3 } \\
2015\end{array}$ & $\begin{array}{r}\text { Ç2 } \\
2015\end{array}$ & $\begin{array}{r}\text { Ç1 } \\
2015\end{array}$ & $\begin{array}{r}\text { Ç4 } \\
2014\end{array}$ & $\begin{array}{r}\text { Ç3 } \\
2014\end{array}$ & $\begin{array}{r}\text { Ç2 } \\
2014\end{array}$ & $\begin{array}{r}\text { Ç1 } \\
2014\end{array}$ \\
\hline $\mathrm{T} 1$ & $-0,03$ & $-0,05$ & $-0,05$ & $-0,04$ & $-0,02$ & $-0,03$ & $-0,05$ & $-0,06$ & $-0,01$ & $-0,06$ & $-0,09$ \\
\hline T2 & 0,11 & 0,11 & 0,13 & 0,16 & 0,14 & 0,13 & 0,13 & 0,14 & 0,14 & 0,10 & 0,09 \\
\hline T3 & 0,01 & $-0,01$ & $-0,03$ & 0,08 & 0,03 & 0,02 & 0,01 & 0,07 & 0,05 & 0,01 & $-0,01$ \\
\hline T4 & 0,17 & 0,20 & 0,30 & 0,30 & 0,31 & 0,40 & 0,45 & 0,58 & 0,40 & 0,41 & 0,44 \\
\hline $\begin{array}{r}Z^{\prime \prime} \\
\text { Skor }\end{array}$ & 0,37 & 0,12 & 0,19 & 1,10 & 0,88 & 0,78 & 0,65 & 1,17 & 1,12 & 0,46 & 0,12 \\
\hline
\end{tabular}


Kaynak: THY A.O Finansal Tabloları

Şekil 1: Altman Z' Modeli- Türk Hava Yolları(THY) Anonim Ortaklığı 2014-2016 Çeyrek Dönem Hesalamaları Grafiği

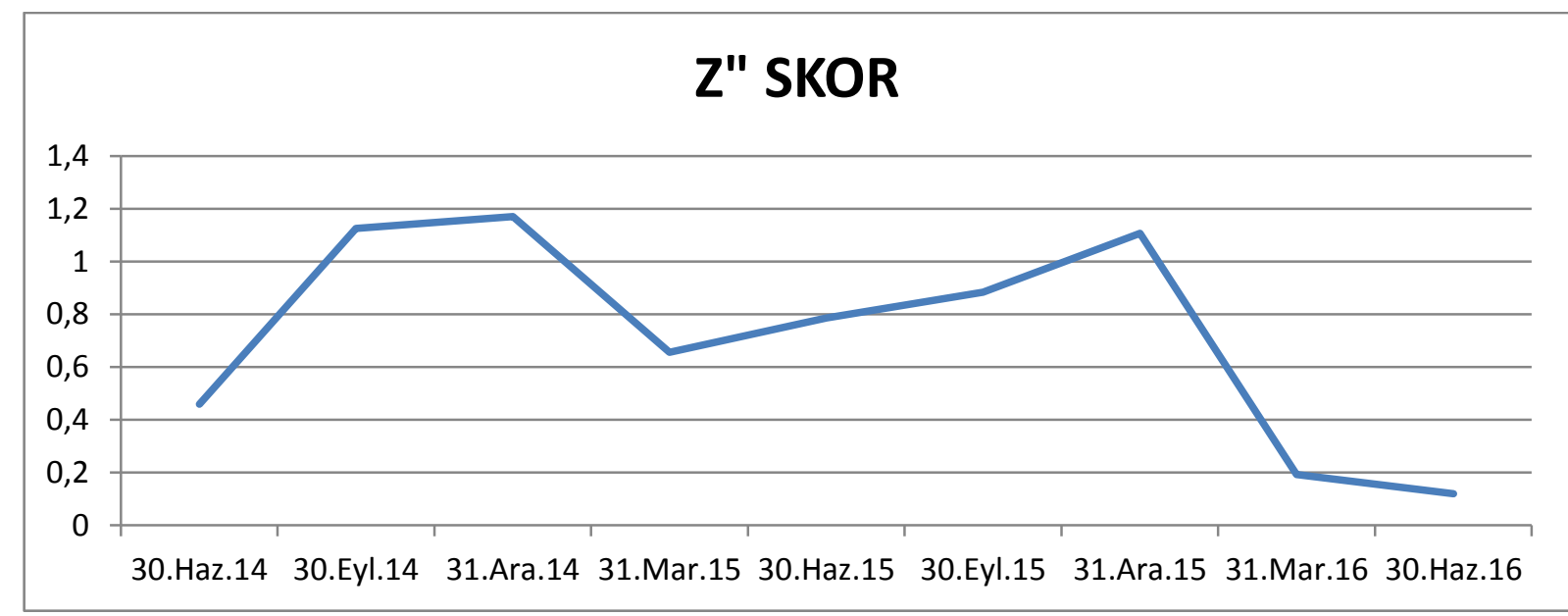

Tablo 6: Airscore Modeli - THY A.O 2014-2016 Çeyrek Sonuçları

\begin{tabular}{|c|c|c|c|c|c|c|c|c|c|c|c|}
\hline $\begin{array}{l}\text { Parame } \\
\text { treler / } \\
\text { Dönem }\end{array}$ & $\begin{array}{l}30 . E \\
\text { yl.16 }\end{array}$ & $\begin{array}{c}30 . \mathrm{H} \\
\text { az.16 }\end{array}$ & $\begin{array}{l}\text { 31.M } \\
\text { ar.16 }\end{array}$ & $\begin{array}{l}\text { 31.A } \\
\text { ra.15 }\end{array}$ & $\begin{array}{l}\text { 30.E } \\
\text { yl.15 }\end{array}$ & $\begin{array}{l}30 . H \\
\text { az.15 }\end{array}$ & $\begin{array}{l}\text { 31.M } \\
\text { ar.15 }\end{array}$ & $\begin{array}{l}\text { 31.A } \\
\text { ra.14 }\end{array}$ & $\begin{array}{l}\text { 30.E } \\
\text { yl.14 }\end{array}$ & $\begin{array}{l}30 . \mathrm{H} \\
\text { az.14 }\end{array}$ & $\begin{array}{l}\text { 31.M } \\
\text { ar.14 }\end{array}$ \\
\hline $\mathrm{T} 1$ & 0,0103 & 0,0131 & 0,0275 & $\begin{array}{r}- \\
0,0159\end{array}$ & 0,0147 & $\begin{array}{r}- \\
0,0048\end{array}$ & $\begin{array}{r}- \\
0,0054\end{array}$ & $\begin{array}{r}- \\
0,0175\end{array}$ & 0,0051 & $\begin{array}{r}- \\
0,0069\end{array}$ & 0,0073 \\
\hline $\mathrm{T} 2$ & $\begin{array}{r}4,82 \\
32\end{array}$ & $\begin{array}{r}- \\
4,0321\end{array}$ & $\begin{array}{r}- \\
4,6767\end{array}$ & $\begin{array}{r}4,62 \\
75\end{array}$ & $\begin{array}{r}13,6 \\
896\end{array}$ & $\begin{array}{r}4,27 \\
28\end{array}$ & $\begin{array}{r}- \\
0,4029\end{array}$ & $\begin{array}{r}2,76 \\
20\end{array}$ & $\begin{array}{r}8,81 \\
01\end{array}$ & $\begin{array}{r}3,97 \\
44\end{array}$ & $\begin{array}{r}4,37 \\
95\end{array}$ \\
\hline T3 & $\begin{array}{r}0,33 \\
25\end{array}$ & $\begin{array}{r}0,32 \\
48\end{array}$ & $\begin{array}{r}0,35 \\
64\end{array}$ & $\begin{array}{r}0,42 \\
00\end{array}$ & $\begin{array}{r}0,41 \\
51\end{array}$ & $\begin{array}{r}0,39 \\
71\end{array}$ & $\begin{array}{r}0,41 \\
25\end{array}$ & $\begin{array}{r}0,40 \\
29\end{array}$ & $\begin{array}{r}0,41 \\
37\end{array}$ & $\begin{array}{r}0,33 \\
62\end{array}$ & $\begin{array}{r}0,34 \\
09\end{array}$ \\
\hline$e^{\text {Airscor }}$ & $\begin{array}{r}0,11 \\
68\end{array}$ & $\begin{array}{r}0,11 \\
28\end{array}$ & $\begin{array}{r}0,11 \\
92\end{array}$ & $\begin{array}{r}0,14 \\
65\end{array}$ & $\begin{array}{r}0,14 \\
54\end{array}$ & $\begin{array}{r}0,14 \\
20\end{array}$ & $\begin{array}{r}0,14 \\
72\end{array}$ & $\begin{array}{r}0,13 \\
97\end{array}$ & $\begin{array}{r}0,14 \\
80\end{array}$ & $\begin{array}{r}0,11 \\
92\end{array}$ & $\begin{array}{r}0,12 \\
08\end{array}$ \\
\hline
\end{tabular}

Kaynak: THY A.O mali tabloları

Şekil 2: Airscore Modeli - Türk Hava Yolları (THY) Anonim Ortaklığı 2014-2016 Çeyrek Dönem Hesaplamaları Grafiği

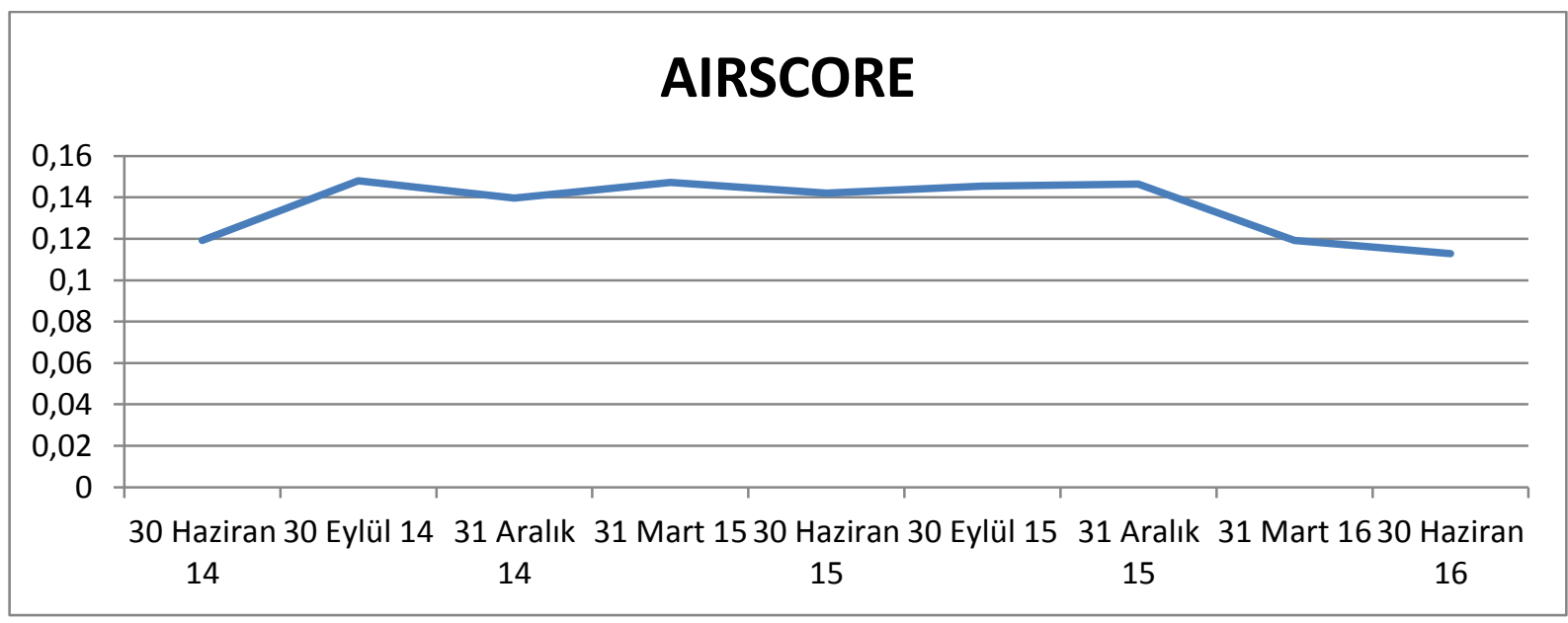

\section{SONUÇ}

Havacılık kolunda faaliyet gösteren işletmelerinin farklı ülkelerde ve dağıtım ağının farklı düzeylerinde varlıklarını sürdürebilmesi, global ve sıkı rekabetçi ortamda finansal açıdan başarılı olabilmesi için karşı karşıya kaldığı risklerin farkında olması ve bunların etkin olarak yönetilmesi sürdürülebilir başarıyı yakaamak açısından çok önemli bir hale gelmiştir. İ̧inde 
bulunduğumuz bilgi toplumunda artan verimler kanunu geçerlidir. Bunun için katma değeri yüksek mal üretiminde uzmanlaşılması, bilgi sayesinde üretimin daha verimli bir hale getirilmesi gerekmektedir (Acar, 2000). Finansal risk konusunda da bilgi teknolojilerinden ve sektöre özel geliştirilen modellerden yararlanarak analiz ve tahminleme yapılması daha sağlıklı sonuçlar alınmasını sağlamaktadır.

Bu çalışma kapsamında yapılan literatür araştırmasında finansal performans ve risk belirleme için kullanılması gereken parametre ve anahtar başarı göstergeleri üzerinde varılmış bir görüş birliği olmadığı görülmüştür. Airscore ve Altman modelleri, finansal başarısızlık tahmini konusunda yapılan önemli çalışmalar arasında kabul edildiğinden çalışma kapsamında ayrıntılı olarak ele alınmıştır. Uygulama bölümünde, Türk Hava Yolları Anonim Ortaklığına ait son 3 seneyi içeren Airscore ve Altman Z" değerlerine yer verilmiştir ve son üç yılı içeren veriler kullanılarak yapılan hesaplamalarda özellikle Altman'a göre son dönemlerde ortaklığın gri alanda(riskli) olduğu görülmektedir.

Riskli jeopolitik ortam, çevredeki çeşitli çatışma ve savaşlar, terör olayları ve paralelinde artan güvenlik kaygısı ve benzeri sebepler ile Türkiye'de turizm sektörü ve havayolu yolcu trafiği olumsuz etkilenmektedir. Söz konusu olumsuz gelişmelerin de etkisiyle zayıf seyreden trafik, Türk Hava Yolları A.O'nun doluluk oranlarının gerilemesine ve birim gelirlerin baskılanmasına neden olmaktadır. Altman modeline göre hesaplanan son 3 yılın çeyreklik verilerine göre gri alanda yer alan THY A.O'nun finansal performansa dikkat etmesi elzemdir. Yapılan analizlere göreTHY Anonim Ortaklığının karlı olan parkurları uzun menzildeki uçuşlardır ve transit yolculardan sağlanan gelirler çok önemlidir.. O yüzden önerimiz geniş gövde filo yatırımları ile uzun menzildeki operasyonu başta olmak üzere kapasite artışları yapılması, yeni hat açılışlarından ile sağlanacak transfer yolcu artışı, hizmet ve servis kalitesinin geliştirilmesi ile "Business Class" yolcu gelirlerinin artırılması ve kargo operasyonunun büyütülmesi ile ortaklık birim gelirlerinin yukarıya çekilmesidir. Bu sayede Z" score değeri de yükselişe geçebilir, skorlar güvenli alana taşınabilir.

\section{KAYNAKLAR}

Acar, 2000. "Bilgi Çağı ekonomisine Teorik Bir Yaklaşım", Dokuz Eylül Üniversitesi i.i..B.F Dergisi, 15, s 87-101.

Akkaya, 2004. "Finansal Rasyolar Yardımıyla Havayolları İşletmelerinin Performansının Değerlendirilmesi”, Dokuz Eylül Üniversitesi i.i.B.F.Dergisi, Cilt 19, Sayı 1, s.3

Altman, 1968. "Financial Ratios, Discriminant Analysis and the Prediction of Corporate Bankruptcy”, The Journal of Finance, 23, 4: 589-609

Altman, Edward I. ve Hotchkiss, Edith(2006). Corporate Financial Distress and Bankruptcy: Predict and Avoid Bankruptcy, Anaylze and Invest in Distressed Debt. 3. bs. New Jersey : John Wiley and Sons., 2006

Clarke John-Paul, Lee Alex, Miller Bruno, "Is air transportation financially sustainable", MIT International Center for Air Transportation, 2004

Dobbins, C., Boehlie M., Miller A., and F. Bernard (2000), "Financial Performance: Measurement and Analysis," Purdue Agricultural Economics Report, March 2000,s. 14-18

Gerede, 2002. "Havayolu taşımacılığında küreselleşme ve havayolu işbirlikleri-THY AO.'da bir uygulama” (Yayımlanmamış Doktora Tezi). Anadolu Üniversitesi Sosyal Bilimler Enstitüsü, Eskişehir, s.15.

Gritta, Adrangi, Davalos, Bright, 2015. "A Review of the History of Air Carrier Bankruptcy Forecasting and the Application of Various Models to the US Airline Industry: 1980-2005", s.3

Karaer, 2015. "Havayolu işletmeciliğinde yakıt maliyetleri ve yönetimi",Gazi Üniversitesi / Sosyal Bilimler Enstitüsü / İşletme Anabilim Dalı / Işletme Bilim Dalı, Doktora Tezi, Ankara.

Sayılgan, 1995. "Finansal Risk Yönetimi". Ankara Üniversitesi SBF Dergisi, 50(01)

McCollough, David, Wright Kardeşler İnsanlığın en Büyük Hayalini Gerçekleştirdiler: UÇTULAR, Lemur Yayınevi, ISBN: 9786059861045, İstanbul, 2016, s.10

Hauschild, 2013. Altman Z-Score: Not Just for Bankruptcy: From Z-Score to “Green Zone" Survivability, Amros Corporation

Topçu Bünyamin, "Finans Dışı Şirketlerde Kurumsal Risk Yönetimi”, Kadir Has Üniversitesi Sosyal Bilimler Enstitüsü Finans Ve Bankacılık Doktora Programı, Doktora Tezi, İstanbul, 2010, s.15

Url: http://investor.turkishairlines.com/documents/ThylnvestorRelations/download/faaliyet_raporu/2014_12_aylik_faaliyet_raporu.pdf> , alındığı tarih: 20.04.2017

Yıldız Ayşe, "Kurumsal Yönetim Endeksi ve Altman Z Skoruna dayalı Lojistik Regresyon Yöntemiyle Şirketlerin Kredi Derecelendirilmesi", Süleyman Demirel Üniversitesi İktisadi ve İdari Bilimler Dergisi, Y. 2014, C.19, S.3, s 71-89, 2014 